Rijken, M., Beek, S. van. About cats and dogs... Reconsidering the relationship between pet ownership and health related outcomes in community-dwelling elderly. Social Indicators Research: 2011, 102(3), $373-388$

\begin{tabular}{|l|l|}
\hline Postprint Version & 1.0 \\
\hline Journal website & http://www.springerlink.com/content/j0612vl6hu46t1u4/ \\
\hline Pubmed link & \\
\hline DOI & $10.1007 /$ s11205-010-9690-8 \\
\hline
\end{tabular}

This is a NIVEL certified Post Print, more info at http://www.nivel.eu

\title{
About Cats and Dogs ... Reconsidering the Relationship Between Pet Ownership and Health Related Outcomes in Community-Dwelling Elderly
}

\author{
MIEKE RIJKEN ${ }^{1}$ AND SANDRA VAN BEEK ${ }^{1}$
}

(1) NIVEL, Netherlands Institute for Health Services Research, Utrecht, The Netherlands

\begin{abstract}
Having a pet has been claimed to have beneficial health effects, but methodologically sound empirical studies are scarce. Small sample sizes and a lack of information about the specific type of pets involved make it difficult to draw unambiguous conclusions. We aimed to shed light on the relationship between pet ownership and several health related outcomes by conducting a survey among a large national sample of community-dwelling elderly in The Netherlands, all suffering from chronic illness or disability. We distinguished several types of pets, focusing on cats and dogs. Pet ownership was associated with a greater chance of using ambulatory mental healthcare, whereas it was not related to self-reported general or mental health. Considering possible mechanisms, associations between pet ownership and the frequency of social contacts or feelings of loneliness were not found. Having a dog increased the likelihood of being healthy active, whereas having a cat showed the opposite. Future research should pay more attention to pet related characteristics, in addition to characteristics of the human sample.
\end{abstract}

\section{INTRODUCTION}

During the last decades a considerable amount of research has been conducted on the relationship between pet ownership and (human) health in general populations as well as in older populations. Research in this area mainly concerns the question whether pets can improve health by functioning as a social resource, either to reduce stress (buffering effect; e.g. Siegel 1990; Allen et al. 2002) or, in line with Weiss' model of social provisions (1974), to satisfy basic social needs such as affection, attachment, companionship and opportunity for nurturance (e.g. Archer 1997). This 'social resource' hypothesis explains the attention that gerontologists and geriatrists have paid to domestic animals. Consider for example the idea of pets as substitutes for a diminishing social network at old age (e.g. Enders-Slegers 2000) or the field of animalassisted therapy (see Filan and Llewellyn-Jones 2006 for an overview in psychogeriatrics).

Functioning as a social resource is not the only way pets can have a positive effect on the health of their owners or carers. Pets may also facilitate social contact with other people (e.g. Headey 1999; Sanders 1999; McNicholas and Collis 2000). People walking their dog often meet other dog owners and talking about dogs can be a easy way to extend the social network with people who share the same interests. In this way, pets do not function as social resources themselves, but can be considered social facilitators. It is likely that especially dogs can facilitate social integration in the neighborhood. Finally, pet ownership is said to improve health by increasing the amount of physical activity of their owners (e.g. Serpell 1991; Raina et al. 1999; Thorpe et al. 2006, Ham and Epping 2006). Again, this may be more applicable to dogs than pets in general.

Many studies have reported benefits of pet ownership in relationship to health (see Edney 1995, for an overview). Health benefits include a reduced risk of cardiovascular disease (Anderson et al. 1992; Allen et al. 2002), better survival rates after a heart attack (Friedmann and Thomas 1995), lower use of general practitioner services (Headey 1999; Headey and Grabka 2007), lower feelings of loneliness and depression (Garrity et al. 1989), and a higher psychological and physical well-being of community-dwelling elderly 
Rijken, M., Beek, S. van. About cats and dogs... Reconsidering the relationship between pet ownership and health related outcomes in community-dwelling elderly. Social Indicators Research: 2011, 102(3), $373-388$

(Raina et al. 1999). More recent studies have however failed to replicate these findings and have found no beneficial effects of pet ownership (McNicholas et al. 2005; Pachana et al. 2005; Parslow et al. 2005; Koivulsilta and Ojanlatva 2006; Clark Cline 2010).

Wells (2007) describes several studies reporting beneficial effects on physical and psychological health, but her overview is specifically concerned with dogs, leaving the potential health related value of other pets out of consideration. Cutt et al. (2007) conclude from a review of the research literature that the evidence suffers from a number of methodological problems. Small sample sizes and non-random samples from specific settings are the most common limitations, which make generalization of the findings of these studies hardly possible. Furthermore, many studies report the benefits of pet ownership, while in fact dogs were the only pets involved or the type of pets studied was not reported at all. Also, the cross-sectional design of most studies makes it hazardous to claim beneficial effects of pet ownership on health, since the same results might suggest that healthy people are more likely to purchase a pet than people who are chronically ill or disabled.

Another limitation mentioned by Cutt and colleagues is the fact that confounding variables are rarely considered or controlled for in the analyses. Several (human) characteristics have been mentioned in the literature to impact on the relationship between pet ownership and health, though mixed results have been found. Some authors suggest that the benefits of especially dog ownership may increase with age, because social networks tend to be more restricted in later years, which makes older people more likely to gain companionship benefits of pets (e.g. Raina et al. 1999). Clark Cline (2010) found gender and marital status to be moderating the relationship between dog ownership and well-being: women and single persons were more likely to benefit from dog ownership. She suggests that 'inattention to variations in marital status and sex may have been one factor in the inconsistency in the literature on pets and well-being'. Parslow et al. 2005 found differences in education level between pet carers and non-carers: those caring for pets had less education than non-carers. Since education level is also known to be an important determinant of health, it might be a confounder of the relationships between pet ownership and health related outcomes as well.

In this study we will examine the relationship between pet ownership and health in the elderly more closely by trying to avoid some of the methodological problems mentioned above. We will study the relationship between pet ownership and several health related outcomes in a large, random sample of elderly $\left(65^{+}\right)$people who all suffer from a long-lasting physical health problem, i.e. a medically diagnosed chronic disease and/or moderate to severe physical disability (visual, hearing or locomotive problems). Thus, all our subjects have some type of objective health problem. In our sample of elderly, we investigate if pet ownership is related to the following health related outcomes: the perceived general health and mental health as rated by the elderly themselves, their level of physical activity, their social contacts and feelings of loneliness, and their use of health services. We will examine whether pet ownership is related to these outcomes, while correcting for differences in socio-demographic characteristics (i.e. age, gender, education level, marital status) and objective physical health indicators. By correcting for differences in objective physical health, we will be able to rule out the part of variation caused by selection bias (i.e. healthier elderly being more likely to purchase and keep a pet than others who are more seriously ill or disabled) and get a more precise assessment of the effects of living with pets on perceived health and health behaviour. Furthermore, we will consider the effects of several types of pets and especially focus on potentially different effects of cats and dogs, the most common pets in Western countries.

In summary, our research questions are:

1. Is pet ownership related to perceived general and mental health of elderly people with a chronic illness or disability, when controlling for socio-demographic and objective health differences between pet owners and non-owners?

2. Is pet ownership related to physical activity, social contacts and loneliness of elderly people with a chronic illness or disability, when controlling for socio-demographic and objective health differences between pet owners and non-owners?

3. Is pet ownership related to the use of health services of elderly people with a chronic illness or disability, when controlling for socio-demographic and objective health differences between pet owners and non-owners? 
Rijken, M., Beek, S. van. About cats and dogs... Reconsidering the relationship between pet ownership and health related outcomes in community-dwelling elderly. Social Indicators Research: 2011, 102(3), $373-388$

\section{METHOD}

\subsection{Sample}

For the purpose of this study, we selected people aged 65 years and over who were participating in the National Panel of people with Chronic illness or Disability (NPCD), a nationwide prospective panel-study in the Netherlands (Rijken et al. 2005; Rijken and Groenewegen 2008). NPCD has been set up to provide information with respect to the consequences of chronic illness and disability from the patient's perspective. NPCD supplies core data on health status, the use of health services and social participation of patients with chronic physical illness or disability.

NPCD consists of about 3,500 people aged 15 years and over with one or more medically diagnosed chronic disease(s) and/or moderate to severe levels of physical disability. The largest part of the panel members are recruited from general practices (see Rijken et al. 2005 for more details). Every year 500 new panel members with a somatic chronic disease are selected via a standardized procedure applied in a random sample of general practices throughout the country. This is done in order to replace panel members who have dropped out or who have participated for the maximum term of 4 years. Additional panel members are selected from several national population surveys on the basis of the presence of moderate to severe physical disability. Because of this procedure, NPCD can be considered a representative sample of the Dutch population of adult, non-institutionalized (physically) chronically ill and/or disabled persons.

Panel members fill in two postal questionnaires per year, in April and October. In October 2005, 3,385 participants of NPCD were sent a questionnaire with questions about their pet ownership and several other variables relevant for the present study. Exactly 3,000 persons (89\%) completed this questionnaire, of whom 1,410 were aged 65 years or older. Of these 1,410 elderly, 1,333 (95\%) also responded to the questionnaire they received in April 2006, which contained some questions used in this study as well.

\subsection{Data}

Data for this study were collected in four ways: (1) medical data provided by the general practitioners of the panel members at inclusion, (2) self-report data regarding socio-demographic and disability characteristics provided by the panel members at inclusion, (3) self-report data regarding pet ownership and health related outcomes provided by the survey of October 2005, and (4) self-report data on outcome variables regarding the use of healthcare in 2005, provided by the survey of April 2006. Since different outcome variables were assessed by the surveys of October 2005 and April 2006, the study design was cross-sectional rather than longitudinal.

\subsubsection{Pet Ownership}

Participants were asked to report all pets that belonged to their household. On the basis of the list of pets reported, we constructed one variable with five answering options: $0=$ no pet, $1=\operatorname{cat}(\mathrm{s}), 2=\operatorname{dog}(\mathrm{s})$, 3 = cat(s) and $\operatorname{dog}(\mathrm{s})$, and $4=$ other pet(s), no cats or dogs. Only a few elderly with cats and/or dogs also had other pets $(n=14)$. Because of this small number, we did not further specify the groups of cat/dog owners.

\subsubsection{Outcome Variables}

Outcome variables were organized into three categories: perceived health outcomes, outcomes related to physical activity and social contacts, and outcomes related to the use of healthcare.

\subsubsection{Perceived Health Outcomes}

Perceived general health was assessed by one item of the RAND-36 Short-form Health Status Survey (Ware and Sherbourne 1992; Dutch validated version of van der Zee et al. 1996). This item is: 'In general, would you say your health is ...?', with five answering options ranging from poor (1) to excellent (5).

Mental health was assessed by the General Health Questionnaire, 12-items version (GHQ-12; Goldberg 1985; Dutch validated version of Koeter and Ormel 1991). The GHQ has been developed as a screening test for mental disorder and is commonly used as a measure of mental distress. Scores range from 0 to 12; a higher score indicating more mental distress and a higher probability for mental disorder. Cronbach's alpha of the GHQ-12 in this study was .88.

\subsubsection{Outcomes Related to Physical Activity, Social Contacts and Loneliness}


Rijken, M., Beek, S. van. About cats and dogs... Reconsidering the relationship between pet ownership and health related outcomes in community-dwelling elderly. Social Indicators Research: 2011, 102(3), $373-388$

The level of physical activity was assessed by the Short questionnaire to assess health enhancing physical activity (SQUASH; Wendel-Vos et al. 2004). The questionnaire includes questions on four domains of physical activity: commuting activities (walking and bicycling), occupational physical activity, household activity, and leisure time physical activity (walking, bicycling, gardening and sports). Respondents were asked to report the number of days per week, the average time per day and the intensity of their physical activity for each of the domains separately. Based on the SQUASH, we assessed whether or not participants met the Dutch standard of being healthy active, i.e. whether or not people were (at least) moderately physically active for 30 min on at least 5 days per week.

Social contacts were assessed by asking the respondents to report the frequency of social contacts with (1) friends or acquaintances, and (2) neighbours. Contacts were defined as encounters with people not living in the respondent's house and with whom the respondent has a (short) conversation; not just exchange greetings. A five-answers response format was used for both items, ranging from 0 'hardly ever or never' (including 'I do not have friends/acquaintances or neighbours') to 4 'daily'. Based on the two items, a total score was computed with a theoretical range from zero to eight.

Besides the frequency of social contacts, loneliness was assessed by six items of the revised UCLA Loneliness Scale (Russell et al. 1980; Russell 1996). These items are: 'There are people I can talk to', 'I feel isolated from others', 'There are people I can turn to', 'There are people who really understand me', 'I feel part of a group of friends', 'My social relationships are superficial'. The items are scored on a fouranswers response format: never (1), seldom (2), sometimes (3), always (4). After reversing the items 1, 3, 4 and 5 , a total score was computed (theoretical range 6-24) so that higher scores indicate more loneliness. Cronbach's alpha of this six-items version in our sample was .74.

\subsubsection{Outcomes Related to Healthcare Use}

We asked the respondents in April 2006 to assess (1) the number of consultations with their general practitioner(s) in 2005, (2) the number of outpatient visits to medical specialists in 2005 and (3) whether or not they had made use of ambulatory mental healthcare, including social work, in 2005. The formulation of these questions has been derived from a long-lasting population survey conducted by Statistics Netherlands (1996).

\subsubsection{Confounding Variables}

Socio-demographic and objective health characteristics were included in the analyses as confounding variables. Socio-demographic variables were: age, gender, education level and marital status. Education level was divided into three categories: low (vocational training), middle (high school), and high (college or university). Marital status was considered as a dichotomous variable $(0=$ single, including divorced and widowed, 1 = married/cohabiting).

With regard to the health characteristics, we used the GP registration of diagnosed chronic diseases in order to assess the type and number of chronic diseases that were present in our sample as well as the disease duration (time post-diagnosis). Furthermore, the presence, severity and type of physical disability were assessed by the SCP-physical disability indicator (de Klerk et al. 2006), a self-report questionnaire completed at inclusion. With regard to the severity of physical disability, we distinguished between subjects who had no or only mild physical disability, subjects with moderate disability and subjects with severe disability. Three types of disability were distinguished: locomotive problems, sensory (visual or hearing) problems, and both locomotive and sensory problems.

\subsection{Statistical Analysis}

Statistical analyses were performed with use of the software package SPSS 17.0. Descriptive statistics (frequencies, means and standard deviations) were computed regarding the socio-demographic and objective health characteristics of the sample as well as their pet ownership and health related outcomes. Analyses of variance (One-Way ANOVA) were performed to search for differences $(\mathrm{P}<.05)$ between the four groups of pet owners and the group of non-owners on the continuous health related outcome variables. Chi-square tests were performed to search for differences in the distributions of the categorical health related outcome variables among the five groups of pet (non-)owners.

In addition, linear and logistic regression analyses were performed to assess the main effects of pet ownership (independent variable) on the health related outcomes, while correcting for the main effects of 
Rijken, M., Beek, S. van. About cats and dogs... Reconsidering the relationship between pet ownership and health related outcomes in community-dwelling elderly. Social Indicators Research: 2011, 102(3), $373-388$

potentially confounding variables (gender, age, education level, marital status, number and type of chronic diseases, type and severity of physical disability).

\section{RESULTS}

\subsection{Description of the Study Sample}

Table 1 contains descriptive statistics regarding the socio-demographic and objective health characteristics of the study sample. The table shows that the majority of the elderly were female (60\%), which is close to the gender distribution of the total Dutch population aged 65 and over: 58\% females in 2005 (Statistics Netherlands 2008). Notice that half of our sample were aged 75 years or older. The percentages of low educated and single persons were relatively high, which can be explained by the fact that our sample consisted of a substantial number of very old people. One of five respondents had a first diagnosis of cardiovascular disease. Diabetes, asthma/COPD and arthritis were also frequently occurring (index) diseases. About $46 \%$ had been diagnosed with more than one chronic disease. Most chronically ill in our sample had been diagnosed many years ago, with an average time post-diagnosis (computed from the date of diagnosis of the index disease) of 13 years. A third reported no or only mild physical disability, whereas almost a quarter reported severe disability. Most respondents reporting moderate to severe physical disability experienced locomotive problems only, but also a substantial part experienced both locomotive and sensory problems.

\section{[TABLE 1]}

\subsection{Pet Ownership}

Twenty percent of the elderly had one or more pets (Table 2). Cats and dogs were both present in about $9 \%$ of the households. Twenty-seven respondents reported to have one or more cats as well as one or more dogs. Three percent of the elderly reported not to have a cat or dog, but to have one or more other pets such as birds, fish, rabbits and rodents.

\section{[TABLE 2]}

\subsection{Health Related Outcomes}

Table 2 also contains descriptive information about the health related outcome variables. The table shows that half of our respondents perceived their general health as moderate or poor. GHQ-12 scores of our sample were somewhat higher than those found in a nationwide reference sample of Dutch elderly (65+) in 2001, but slightly lower than those found among a sample of Dutch chronically ill aged 15 years and over in 1998 (Verhaak et al. 2005). Regarding physical activity, almost half of our respondents met the standard of being healthy active, which is lower than the percentage found in the total Dutch population aged 65 and over: 58\% in 2005 (Statistics Netherlands 2009). The mean score of 4.6 for frequency of social contacts suggests that most elderly of our sample had face-to-face contacts with neighbours, friends or acquaintances at least once a month, but not every week. The mean score of 10.96 on our six-items loneliness scale was very similar to the mean scores found by Cutrona et al. (1986) in a small sample of American elderly on a 20-items version of the UCLA Loneliness scale $(\mathrm{M}=37.4$ at time 1 and $\mathrm{M}=37.5$ at time 2). Looking at the figures on healthcare use, it can be concluded that our elderly respondents visited their GP on the average more often $(\mathrm{M}=5.7$ times per year) than did the general Dutch population aged 65 and over (5.2 times in 2005;Statistics Netherlands 2009), but especially the relatively large number of outpatient visits to medical specialists comes to the fore. The use of ambulatory mental healthcare among our respondents was low, though higher than in the total Dutch population aged 65 and over in 2003: 3.6\% (computed from GGZ Nederland 2005).

\subsection{Comparison of Groups of Pet (non-)Owners}

In Table 3 the results of the bivariate analyses (One-Way ANOVA and chi-square tests) are presented. It shows that the five groups of pet (non-)owners do not differ significantly from each other regarding their scores on the perceived health outcomes. The same holds for our outcomes on social contacts and 
Rijken, M., Beek, S. van. About cats and dogs... Reconsidering the relationship between pet ownership and health related outcomes in community-dwelling elderly. Social Indicators Research: 2011, 102(3), $373-388$

loneliness. The distributions of the physical activity scores are however significantly different among the five groups. Of the elderly living with a dog $70 \%$ meet the standard of being healthy active, which is a considerable larger part than among the group of non-owners (almost 50\%) or the groups of elderly with cats or other pets $(<40 \%)$.

\section{[TABLE 3]}

Pet (non-)owners do not significantly differ from each other when it comes to the number of GP consultations or outpatient visits to medical specialists. However there is a difference in the use of ambulatory mental healthcare between the five groups. More than ten percent of the cat or dog owners reported to have had contact with ambulatory mental healthcare in 2005, whereas this was about $5 \%$ among those not having a pet and 7\% among those with other pets than cats or dogs.

\subsection{Impact of Pet Ownership on Outcomes Variables}

Differences between groups of pet (non-)owners as pointed out above might be due to differences between the groups on other variables than pet ownership, for instance gender, marital status, type of chronic illness or severity of physical disability. In order to get a precise estimation of the impact of pet ownership, we corrected the regression effects of pet ownership on our outcome variables by including socio-demographic and objective health characteristics as confounding variables in our analyses. The results are described in Table 4 (perceived health outcomes and outcomes related to physical activity and social well-being) and Table 5 (outcomes related to the use of healthcare). For reasons of brevity, these tables only show confounding variables that have significant effects on one or more of the outcome variables in the table, in addition to the effects of pet ownership (standardized regression coefficients or odds ratios).

\section{[TABLE 4, 5]}

Having a pet does not significantly contribute to the explanation of general health, mental health, the frequency of social contacts and loneliness in the elderly (Table 4). But when it comes to physical activity, pet ownership is of predictive value. Elderly who have a dog are more likely to get enough physical exercise than elderly without a dog. Having a cat does not have such a positive effect; on the contrary, the effect of cat ownership is adverse.

Regarding the use of healthcare (Table 5), pet ownership does not contribute to the explanation of the number of GP contacts or outpatient visits to medical specialists of these chronically ill or disabled elderly. However, elderly who have a cat are more likely to use ambulatory mental healthcare services than elderly without pets. This is also true for elderly who also have dogs beside their cats.

\subsection{Impact of Confounding Variables}

Although we focused in this study on the effects of pet ownership, we will briefly describe the effects of the socio-demographic and objective health characteristics that were included in the regression analyses. Regarding the socio-demographic characteristics, gender was not an important predictor except for loneliness: women felt less lonely than men. Older age was significantly related to a perception of a worse general health, better mental health, a smaller chance of being healthy active, less social contacts and less visits to medical specialists. A higher education level was significantly associated with a perception of a better general health and a greater chance of having made use of ambulatory mental healthcare. Finally, being married or cohabiting was significantly related to a better mental health.

Of the objective health characteristics, the severity of physical disability appeared to be an important predictor of almost all outcome variables. Having more severe physical limitations was associated with a perception of a worse general health, more mental health problems, a smaller chance of being healthy active, less social contacts, more loneliness, and a larger number of contacts with general practitioners as well as with medical specialists. In addition, being diagnosed with more chronic diseases resulted in a perception of a worse health and more GP consultations. With regard to the type of chronic disease or the type of disability, there were also some significant effects. For instance, being diagnosed with cancer or with a musculoskeletal disease (other than arthritis) was associated with more mental health problems than being diagnosed with one of the other index diseases, and experiencing a combination of locomotive and sensory limitations increased the likelihood of having had contact with ambulatory mental healthcare services, but it also increased the likelihood of meeting the standard of being healthy active. Perhaps this is 
Rijken, M., Beek, S. van. About cats and dogs... Reconsidering the relationship between pet ownership and health related outcomes in community-dwelling elderly. Social Indicators Research: 2011, 102(3), $373-388$

because of a higher use of exercise therapy by elderly with multiple limitations. Overall, the total set of independent variables were of modest predictive value for the outcome variables (see model statistics).

\subsection{Single Elderly}

Finally, we repeated all analyses for the group of single elderly in our sample $(\mathrm{N}=616)$, speculating that the effects of pet ownership would be more distinct in elderly who do not have a person in the household for companionship or to help them walk the dog. In general, $18.9 \%$ of the single elderly reported to have one or more pets, which is comparable to the percentage found in the total group of elderly. Slightly more single elderly had a cat (9.5\%) and slightly less (7.7\%) had a dog compared to the total group. The same non-significant and significant effects were found in these singles, except for the effect of having a cat (versus not having a pet) in meeting the standard of being healthy active, which was not significant in this group, and the effect of having a dog (versus not having a pet) on the use of mental healthcare, which was significant here. Among the single elderly, having a dog also increased the likelihood of having had contact with mental healthcare services significantly.

\section{Discussion}

This study contributes to the scientific knowledge of the beneficial or unbeneficial effects of pet ownership on health related outcomes in elderly populations. Our sample was special in the sense that all respondents suffered from chronic illness or disability. At the same time chronic illness and disability are not special at all in older populations; living with chronic illness and/or disability at the age of 65 and over appears to be more common than being healthy at that age (Hoeymans et al. 2008). Moreover, with increasing age, multi-morbidity rates increase as well (Van den Akker et al. 1998). Given the strengths of this study (the large nationwide representative sample of community-dwelling chronically ill/disabled elderly, the distinction made between several types of pets and the analyses controlled for confounding variables), we believe that our results should be rated at their true value.

We could not find evidence that having a pet is beneficial to perceived health of the elderly. Obviously we could not assess the impact of pet ownership on the onset of chronic disease or disability in this sample, but elderly who are already chronically ill or disabled do not perceive their general health as better when they have a pet. Pet ownership was neither related to mental health in our study. In view of this result, it is intriguing that the use of ambulatory mental healthcare appeared to be different among pet owners and nonowners. Pet owners, more specifically cat owners, have more often contact with ambulatory mental healthcare services than non-owners. This result cannot be explained by differences in socio-demographic and health characteristics between groups of pet (non-)owners, since the effect of pet ownership was corrected for the effects of these characteristics. In addition to cat ownership, only education level and the experience of multiple disabilities significantly predicted the use of ambulatory mental healthcare. One might wonder whether personality characteristics, which were not included in this study, could be responsible for the effect of cat ownership on the use of mental healthcare. In general, little attention has been paid to personality traits associated with pet ownership (Parslow et al. 2005). It has been argued in the past that pet owners are likely to have lower levels of neuroticism and higher levels of extraversion, but according to Parslow and colleagues, support for these hypotheses is limited. An early study showed that pet owners had even higher levels of neuroticism than non-owners, suggesting that pet owners were less psychologically healthy (Cameron et al. 1966). However, Johnson and Rule (1991) found no differences between pet owners and non-owners with regard to neuroticism, extraversion, self-esteem and social behaviour. So far, there is no evidence that elderly cat owners are less psychologically healthy than elderly who do not have a cat.

Our results regarding the variables that refer to potential mechanisms show that physical activity was significantly predicted by pet ownership, but social contacts with friends, acquaintances and neighbours and feelings of loneliness were not. The effect of pet ownership on physical activity appears to be highly dependent on the type of pet involved. Cats and dogs seem to have almost opposite effects on the physical activity level of their owners, with dogs increasing the chance of being healthy active and cats decreasing this chance. These insights are important when reconsidering the inconclusive results on the beneficial effects of pets on health described in the literature so far.

We also wish to make some remarks on our findings pointing to the absence of an effect of pet ownership on the use of general practice and specialized medical care. It is important to notice that all our respondents had some type of physical health problem, i.e. chronic disease or physical disability. The descriptive 
Rijken, M., Beek, S. van. About cats and dogs... Reconsidering the relationship between pet ownership and health related outcomes in community-dwelling elderly. Social Indicators Research: 2011, 102(3), $373-388$

statistics show that our sample consisted of elderly with a relatively high consumption of medical care, which is a natural result of their objective health status. On the basis of this study we cannot conclude that pet ownership does not have an effect on medical consumption in general. But what we can conclude is that having a pet does not increase or decrease the number of GP consultations or outpatient visits with medical specialists of elderly chronically ill or disabled patients, who are already high consumers of medical care.

Apart from the strengths already mentioned, our study has some limitations as well. Although we had data from several measuring moments, the study design was still cross-sectional. Pet ownership and most outcome variables were assessed at the same moment (October 2005); outcomes related to healthcare use were assessed 6 months later (April 2006), but also covered 2005. Due to the cross-sectional nature of the study, causal effects of pet ownership on health related outcomes could not be established; the term 'effect' we used here could only be interpreted in a statistical sense.

A second limitation is that we did not assess the strength of pet attachment, which might moderate the relationship between pet ownership and well-being. In addition, we do know how long the pet owners in our sample had their pets, and whether or not they had their pets already before the onset of the chronic disease or disability. We know however that the chronically ill in our sample had an average time postdiagnosis of 13 years. Assuming a life expectancy of 10-13 years for most dogs and about 15 years for (indoor) cats, it seems likely that most pet owners were already chronically ill or disabled when they purchased their pets. It is of course possible that participants in our study had had other pets before the pet(s) they reported in October 2005. Nevertheless, also in those cases the pets reported on the questionnaire will probably be purchased after the onset of the chronic illness or disability. Furthermore, we could not make sense of the effects of having both cats and dogs on our outcome variables due to the small group of elderly having both types of pets in our study.

Concluded, pets can be good company for elderly with a chronic illness or disability, but they do not contribute to perceived health or social well-being. Having a dog can help elderly to achieve a healthy level of physical activity. Pet ownership, especially cat ownership, is related to a greater chance of making use of ambulatory mental healthcare. How and why this is deserves further scientific attention. Future research should not only specify characteristics of the (human) sample, but also specify pet related characteristics such as the type of pet involved, the level of pet attachment and the length of time for which pets have been part of the household.

\section{ACKNOWLEDGMENTS}

This study forms part of the research programme National Panel of people with Chronic illness or Disability (NPCD). NPCD is funded by the Netherlands ministry of Health, Welfare and Sports, and the Netherlands ministry of Social Affairs and Employment.

\section{REFERENCES}

Allen, K., Blascovich, J., \& Mendes, W. B. (2002). Cardiovascular reactivity and the presence of pets, friends, and spouses: The truth about cats and dogs. Psychosomatic Medicine, 64, 727-739.

Anderson, W. P., Reid, C. M., \& Jennings, G. L. (1992). Pet ownership and risk factors for cardiovascular disease. The Medical Journal of Australia, 157, 298-301.

Archer, J. (1997). Why do people love their pets? Evolution and Human Behavior, 18, 237-259.

Cameron, P., Conrad, C., Kirkpatrick, D., \& Bateen, R. (1966). Pet ownership and sex as determinants of stated affect toward others and estimates of other's regard of self. Psychological Reports, 30, 884-886.

Clark Cline, K. M. (2010). Psychological effects of dog ownership: Role strain, role enhancement, and depression. Journal of Social Psychology, 150, 117-131.

Cutrona, C., Russell, D., \& Rose, J. (1986). Social support and adaptation to stress by the elderly. Journal of Psychology and Aging, 1, 47-54.

Cutt, H., Giles-Corti, B., Knuiman, M., \& Burke, V. (2007). Dog ownership, health and physical activity: A critical review of the literature. Health and Place, 13, 261-272.

de Klerk, M., ledema, J., \& van Campen, C. (2006). SCP-maat voor lichamelijke beperkingen op basis van AVO 2003. [SCP-physical disability indicator on the basis of AVO 2003]. The Hague, The Netherlands: Netherlands Institute for Social Research.

Edney, A. T. B. (1995). Companion animals and human health: An overview. Journal of the Royal Society of Medicine, 88, 704-708. 
Rijken, M., Beek, S. van. About cats and dogs... Reconsidering the relationship between pet ownership and health related outcomes in community-dwelling elderly. Social Indicators Research: 2011, 102(3), $373-388$

Enders-Slegers, M. J. (2000). The meaning of companion animals: Qualitative analysis of the life histories of elderly cat and dog owners. In A. L. Podberscak, E. S. Paul, \& J. A. Serpell (Eds.), Companion animals and us: Exploring the relationships between people and pets (pp. 237-256). New York: Cambridge University Press.

Friedmann, E., \& Thomas, S. A. (1995). Pet ownership, social support, and one-year survival after acute myocardial infarction in the Cardiac Arrhythmia Suppression Trial (CAST). American Journal of Cardiology, 76, 1213-1217.

Garrity, T. F., Stallones, L., Marx, M. B., \& Johnson, T. P. (1989). Pet ownership and attachment as supportive factors in the health of the elderly. Anthrozoos, 1989.

Goldberg, D. P. (1985). Identifying psychiatric illness among general medical patients. British Medical Journal, 291, 161-162.

GGZ Nederland. (2005). Kerncijfers uit de ggz $2001 \mathrm{t} / \mathrm{m}$ 2003. [Core data from mental healthcare 20012003]. Amersfoort, The Netherlands: GGZ Nederland.

Filan, S. L., \& Llewellyn-Jones, R. H. (2006). Animal-assisted therapy for dementia: A review of the literature. International Psychogeriatrics, 18, 597-611.

Ham, S. A., \& Epping, J. (2006). Dog walking and physicial activity in the United States. Preventing Chronic Disease, 3, 1-7.

Headey, B. (1999). Health benefits and health cost savings due to pets: Preliminary estimates from an Australian national survey. Social Indicators Research, 47, 233-243.

Headey, B., \& Grabka, M. M. (2007). Pets and human health in Germany and Australia: National longitudinal results. Social Indicators Research, 80, 297-311.

Hoeymans, N., Schellevis, F. G., \& Wolters, I. (2008). Hoeveel mensen hebben één of meer chronische ziekten? [How many people have one or more chronic diseases?] (In: Volksgezondheid Toekomst Verkenning, Nationaal Kompas Volksgezondheid. RIVM, http://www.nationaalkompas.nl/, 12 December 2008, Bilthoven, The Netherlands).

Johnson, S. B., \& Rule, W. R. (1991). Personality characteristics and self-esteem in pet owners and nonowners. International Journal of Psychology, 26, 241-252.

Koeter, M. W. J., \& Ormel, J. (1991). General Health Questionnaire. Lisse, The Netherlands: Swets \& Zeitlinger. (in Dutch).

Koivulsilta, L. K., \& Ojanlatva, A. (2006). To have or not to have a pet for better health. PLos ONE, 1, 1-9.

McNicholas, J., \& Collis, G. M. (2000). Dogs as catalysts for social interactions: Robustness of the effect. British Journal of Psychology, 91, 61-70.

McNicholas, J., Gilby, A., Rennie, A., Ahmedzai, S., Dono, J., \& Ormerod, E. (2005). Pet ownership and human health: A brief review of evidence and issues. British Medical Journal, 331, 1252-1254.

Pachana, N. A., Ford, J. H., Andrew, B., \& Dobson, A. J. (2005). Relations between companion animals and self-reported health in older women: Cause, effect or artefact? International Journal of Behavioral Medicine, 12, 103-110.

Parslow, R. A., Jorm, A. F., Christensen, H., Rodgers, B., \& Jacomb, P. (2005). Pet ownership and health in older adults: Findings from a survey of 2,551 community-based Australians aged 60-64. Gerontology, 51, 40-47.

Raina, P., Waltner-Toews, D., Bonnett, B., Woodward, C., \& Abernathy, T. (1999). Influence of companion animals on the physical and psychological health of older people: An analysis of a one-year longitudinal study. Journal of the American Geriatric Society, 47, 323-329.

Rijken, M., \& Groenewegen, P. P. (2008). Money does not bring well-being, but it does help! The relationship between financial resources and life satisfaction of the chronically ill mediated by social deprivation and loneliness. Journal of Community \& Applied Social Psychology, 18, 39-53.

Rijken, M., van Kerkhof, M., Dekker, J., \& Schellevis, F. G. (2005). Comorbidity of chronic diseases. Effects of disease pairs on physical and mental functioning. Quality of Life Research, 14, 45-55.

Russell, D. W. (1996). UCLA Loneliness Scale (version 3): Reliability, validity, and factor structure. Journal of Personality Assessment, 66, 20-40.

Russell, D., Peplau, L. A., \& Cutrona, C. E. (1980). The Revised UCLA Loneliness Scale: Concurrent and discriminant validity evidence. Journal of Personality and Social Psychology, 39, 472-480.

Sanders, C. R. (1999). Understanding dogs: Living and working with canine companions. Philadelphia: Temple University Press.

Serpell, J. (1991). Beneficial effects of pet ownership on some aspects of human health and behavior. Journal of the Royal Society of Medicine, 84, 717-720.

Siegel, J. M. (1990). Stressful life events and the use of physician services among the elderly: The moderating effects of pet ownership. Journal of Personality and Social Psychology, 58, 1081-1086.

Statistics Netherlands. (1996). Netherlands Health Interview Survey 1981-1995. The Hague, The Netherlands: Sdu publishers/CBS-publications. 
Rijken, M., Beek, S. van. About cats and dogs... Reconsidering the relationship between pet ownership and health related outcomes in community-dwelling elderly. Social Indicators Research: 2011, 102(3), 373-388

Statistics Netherlands. (2008). http://www.statline.cbs.nl/ Netherlands population at 1 January 2005, data adapted August 19th, 2008.

Statistics Netherlands. (2009). http://www.statline.cbs.nl/ Reported health and life style 2005, table changed on March 16, 2009.

Thorpe, R. J., Kreisle, R. A., Glickman, L. T., Simonsick, E. M., Newman, A. B., \& Kritchevsly, S. (2006). Physical activity and pet ownership in year 3 of the Health ABC study. Journal of Aging and Physical Activity, 14, 154-168.

van den Akker, M., Buntinx, F., Metsemakers, J. F. M., Roos, S., \& Knottnerus, J. A. (1998). Multimorbidity in general practice: Prevalence, incidence, and determinants of co-occurring chronic and recurrent diseases. Journal of Clinical Epidemiology, 51, 367-375.

van der Zee, K. I., Sanderman, R., Heyink, J. W., \& de Haes, H. (1996). Psychometric qualities of the RAND 36-Item health survey 1.0: A multidimensional measure of general health status. International Journal of Behavioral Medicine, 3, 104-122.

Verhaak, P. F. M., Heijmans, M. J. W. M., Peters, L., \& Rijken, M. (2005). Chronic disease and mental disorder. Social Science and Medicine, 60, 789-797.

Ware, J. E., \& Sherbourne, C. D. (1992). The RAND-36 short-form health status survey: I. Conceptual framework and item selection. Medical Care, 30, 473-481.

Weiss, R. S. (1974). The provisions of social relationships. In Z. Rubin (Ed.), Doing unto others (pp. 17-26). Englewood Cliffs, NJ: Prentice-Hall.

Wells, D. L. (2007). Domestic dogs and human health: An overview. British Journal of Health Psychology, 4, 145-156.

Wendel-Vos, G. C. W., Schuit, A. J., de Niet, R., Boshuizen, H. C., Saris, W. H. M., \& Kromhout, D. (2004). Factors of the physical environment associated with walking and bicycling. Medicine and Science in Sports and Exercise, 36, 725-730. 
Rijken, M., Beek, S. van. About cats and dogs... Reconsidering the relationship between pet ownership and health related outcomes in community-dwelling elderly. Social Indicators Research: 2011, 102(3), 373-388

\section{[TABLES]}

Table 1 Socio-demographic and health related characteristics $(N=1,410)$

\begin{tabular}{|c|c|c|c|c|c|}
\hline & $N$ & $n$ & $\%$ & $M$ & SD \\
\hline Gender & 1,410 & & & & \\
\hline Male & & 564 & 40.0 & & \\
\hline Female & & 846 & 60.0 & & \\
\hline Age (in years) & 1,410 & & & 74.58 & 6.38 \\
\hline $65-74$ & & 710 & 50.4 & & \\
\hline 75 and older & & 700 & 49.6 & & \\
\hline Education level & 1,323 & & & & \\
\hline Low & & 746 & 56.4 & & \\
\hline Moderate & & 449 & 33.9 & & \\
\hline High & & 128 & 9.7 & & \\
\hline Marital status & 1,398 & & & & \\
\hline Single (incl. widowed, divorced) & & 616 & 44.1 & & \\
\hline Married/cohabiting & & 782 & 55.9 & & \\
\hline Type of chronic illness (index disease ${ }^{\mathrm{a}}$ ) & 1,410 & & & & \\
\hline Cardiovascular & & 295 & 20.9 & & \\
\hline Cancer & & 51 & 3.6 & & \\
\hline Asthma/COPD & & 169 & 12.0 & & \\
\hline Diabetes & & 184 & 13.0 & & \\
\hline Arthritis & & 149 & 10.6 & & \\
\hline Other musculoskeletal & & 104 & 7.4 & & \\
\hline Neurological & & 49 & 3.5 & & \\
\hline Other & & 188 & 13.3 & & \\
\hline No chronic disease or unknown & & 221 & 15.7 & & \\
\hline Number of chronic diseases diagnosed & 1,410 & & & & \\
\hline None or unknown & & 221 & 15.7 & & \\
\hline One & & 544 & 38.6 & & \\
\hline Two & & 342 & 24.3 & & \\
\hline Three & & 182 & 12.9 & & \\
\hline Four or more & & 121 & 8.6 & & \\
\hline Time post-diagnosis (if chronic disease diagnosed) & 1,154 & & & 13.42 & 11.69 \\
\hline Severity of physical disability & 1,291 & & & & \\
\hline Absent or mild & & 446 & 34.5 & & \\
\hline Moderate & & 544 & 42.1 & & \\
\hline Severe & & 301 & 23.3 & & \\
\hline Type of (moderate/severe) disability & 1,310 & & & & \\
\hline Absent or mild & & 446 & 34.0 & & \\
\hline Locomotive only & & 571 & 43.6 & & \\
\hline Sensory only & & 40 & 3.1 & & \\
\hline Locomotive and sensory & & 253 & 19.3 & & \\
\hline
\end{tabular}

$N$ sample size, $n$ number, $M$ mean, $S D$ standard deviation

a The index disease is the chronic disease that had been diagnosed first, in case of more than one chronic disease 
Rijken, M., Beek, S. van. About cats and dogs... Reconsidering the relationship between pet ownership and health related outcomes in community-dwelling elderly. Social Indicators Research: 2011, 102(3), 373-388

Table 2 Descriptive statistics of pet ownership and outcome variables

\begin{tabular}{|c|c|c|c|c|c|}
\hline & $N$ & $n$ & $\%$ & Mean & $\mathrm{SD}$ \\
\hline Pet ownership & 1,397 & & & & \\
\hline No pet & & 1,116 & 79.9 & & \\
\hline Cat(s) & & 98 & 7.0 & & \\
\hline $\operatorname{Dog}(s)$ & & 108 & 7.7 & & \\
\hline Cat(s) and $\operatorname{dog}(\mathrm{s})$ & & 27 & 1.9 & & \\
\hline Other pets, no cats or dogs & & 48 & 3.4 & & \\
\hline General health (range 1-5) & 1,348 & & & 2.50 & 0.69 \\
\hline Poor & & 57 & 4.2 & & \\
\hline Moderate & & 633 & 47.0 & & \\
\hline Good & & 593 & 44.0 & & \\
\hline Very good & & 51 & 3.8 & & \\
\hline Excellent & & 14 & 1.0 & & \\
\hline Mental health (morbidity; range $0-12$ ) & 1,341 & & & 1.94 & 2.97 \\
\hline Score $>2$ & & 376 & 28.0 & & \\
\hline \multicolumn{6}{|l|}{ Outcomes related to physical activity and social well-being } \\
\hline Healthy active according to standard & 1,353 & 647 & 47.8 & & \\
\hline Frequency of social contact (range $0-8$ ) & 1,364 & & & 4.56 & 2.00 \\
\hline Loneliness (range 6-24) & 1,328 & & & 10.96 & 3.39 \\
\hline \multicolumn{6}{|l|}{ Outcomes related to healthcare use } \\
\hline Number of GP consultations per year (2005) & 1,229 & & & 5.66 & 5.08 \\
\hline Number of outpatient visits to MS per year (2005) & 1,253 & & & 4.53 & 5.21 \\
\hline Use of ambulatory mental health care (2005) & 990 & 67 & 6.8 & & \\
\hline
\end{tabular}


Rijken, M., Beek, S. van. About cats and dogs... Reconsidering the relationship between pet ownership and health related outcomes in community-dwelling elderly. Social Indicators Research: 2011, 102(3), $373-388$

Table 3 Descriptives of and differences in health related outcomes among pet (non)owners

\begin{tabular}{|c|c|c|c|c|c|}
\hline & No pet & Cat & Dog & Cat and dog & Other \\
\hline \multicolumn{6}{|c|}{ Perceived health outcomes } \\
\hline \multicolumn{6}{|c|}{ General health } \\
\hline$M(S D)$ & $2.51(0.70)$ & $2.56(0.63)$ & $2.51(0.71)$ & $\begin{array}{l}2.22(0.60) \\
F(4,1330)\end{array}$ & $\begin{array}{l}2.43(0.63) \\
7, P=.28\end{array}$ \\
\hline \multicolumn{6}{|c|}{ Mental health (morbidity) } \\
\hline$M(S D)$ & $1.94(2.99)$ & $2.17(3.06)$ & $1.75(2.54)$ & $\begin{array}{l}1.95(3.08) \\
F(4,1323)\end{array}$ & $\begin{array}{c}1.79(3.27) \\
5, P=.89\end{array}$ \\
\hline
\end{tabular}

Outcomes related to physical activity and social well-being

Healthy active according to standard

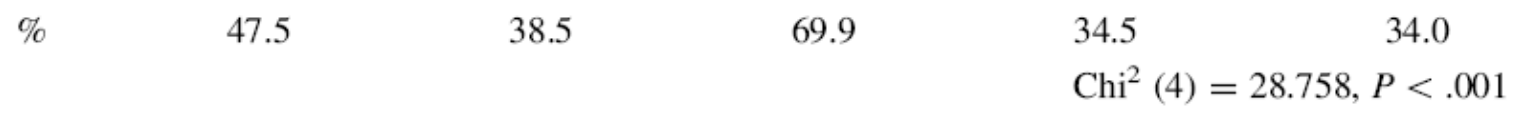

Frequency of social contacts

\begin{tabular}{|c|c|c|c|c|c|}
\hline$M(S D)$ & $4.56(2.00)$ & $4.48(2.03)$ & $4.54(2.01)$ & $4.31(1.98)$ & $4.70(2.01)$ \\
\hline
\end{tabular}

Loneliness

$\begin{array}{lllll}M(S D) & 10.92(3.42) & 10.89(3.14) & 11.06(3.20) & 11.96(3.83)\end{array} \quad \begin{aligned} & 11.40(3.51) \\ & \end{aligned}$

Outcomes related to healthcare use

Number of GP consultations

$$
M(S D) \quad 5.57(5.01) \quad 5.74(4.13) \quad 5.93(4.90) \quad 6.64(10.17) \quad 6.46(5.48)
$$

Number of outpatient MS visits
$M(S D)$
$4.57(5.15)$
$4.16(4.88)$
$4.92(6.72)$
4.32 (3.82)
$3.80(4.35)$
$F(4,1239)=0.483, P=.75$

Use of ambulatory mental healthcare
$\%$
5.4
13.7
10.1
15.8
6.5
$\mathrm{Chi}^{2}(4)=11.627, P=.02$

$M$ mean, $S D$ standard deviation 
Rijken, M., Beek, S. van. About cats and dogs... Reconsidering the relationship between pet ownership and health related outcomes in community-dwelling elderly. Social Indicators Research: 2011, 102(3), $373-388$

Table 4 Impact of pet ownership on outcome variables, standardized regression coefficients (results of multiple linear regression analyses) or odds ratios (results of multiple logistic regression analyses) of presence of pet (versus no pet) and significance $(P<.05)$, corrected for socio-demographic and objective health characteristics

\begin{tabular}{|c|c|c|c|c|}
\hline \multicolumn{5}{|l|}{ Perceived health outcomes } \\
\hline & \multicolumn{2}{|c|}{ General health } & \multicolumn{2}{|c|}{ Mental health (morbidity) } \\
\hline & $\beta$ & $\mathrm{P}$ & $\beta$ & $\mathrm{P}$ \\
\hline \multicolumn{5}{|l|}{ No pet (ref). } \\
\hline Cat & .02 & .35 & .03 & .38 \\
\hline Dog & -.03 & .20 & -.01 & .71 \\
\hline Cat and dog & -.03 & .25 & -.03 & .32 \\
\hline Other pet (than cat or dog) & -.02 & .40 & -.02 & .49 \\
\hline \multicolumn{5}{|l|}{ Confounding variables $^{\mathrm{a}}$} \\
\hline Age & .09 & .002 & -.10 & .001 \\
\hline Education level & .06 & .02 & & \\
\hline Married/cohabiting & & & -.06 & .05 \\
\hline Diagnosis: cancer & & & .07 & .05 \\
\hline Diagnosis: musculoskeletal & & & .08 & .03 \\
\hline Number of chronic diseases & -.07 & .05 & & \\
\hline Severity of phys. disability & -.35 & $<001$ & .24 & $<001$ \\
\hline Locomotive limitations & -.16 & .002 & & \\
\hline \multicolumn{5}{|l|}{ Model statistics } \\
\hline$F(d f)$ & $F(21,1132)=20.35$ & $<001$ & $F(21,1131)=6.72$ & $<001$ \\
\hline OLS $R^{2}$ & .27 & & .11 & \\
\hline
\end{tabular}

Outcomes related to physical activity and social well-being

\begin{tabular}{|c|c|c|c|c|c|c|}
\hline & \multicolumn{2}{|l|}{ Healthy active } & \multicolumn{2}{|l|}{ Social contacts } & \multicolumn{2}{|l|}{ Loneliness } \\
\hline & OR & $\mathrm{P}$ & $\beta$ & $\mathrm{P}$ & $\beta$ & $\mathrm{P}$ \\
\hline \multicolumn{7}{|l|}{ No pet (ref). } \\
\hline Cat & 0.59 & .05 & -.01 & .70 & .02 & .50 \\
\hline Dog & 2.77 & .001 & -.01 & .69 & -.00 & .97 \\
\hline Cat and dog & 0.79 & .62 & -.03 & .27 & .04 & .14 \\
\hline Other pet (than cat or dog) & 0.50 & .06 & .01 & .72 & .01 & .63 \\
\hline \multicolumn{7}{|l|}{ Confounding variables ${ }^{\mathrm{a}}$} \\
\hline Age & 0.95 & $<.001$ & -.13 & $<001$ & & \\
\hline Gender: female & & & & & -.07 & .03 \\
\hline Severity of phys. disability & 0.25 & $<.001$ & -.19 & .001 & .20 & .001 \\
\hline Locomotive and sensory lim. & 2.35 & .009 & & & & \\
\hline \multicolumn{7}{|l|}{ Model statistics } \\
\hline$F / \chi^{2}(d f)$ & $\chi^{2}(21)=240.71$ & $<.001$ & $F(21,1147)=2.73$ & $<001$ & $F(21,1118)=2.53$ & $<001$ \\
\hline OLS $R^{2}$ /Nagelkerke $R^{2}$ & .25 & & .05 & & .05 & \\
\hline
\end{tabular}

Corrected for gender, age, education level, marital status, number and type of chronic diseases, type and severity of physical disability

a Only variables with significant effects shown 
Rijken, M., Beek, S. van. About cats and dogs... Reconsidering the relationship between pet ownership and health related outcomes in community-dwelling elderly. Social Indicators Research: 2011, 102(3), $373-388$

Table 5 Impact of pet ownership on outcomes related to the use of healthcare, standardized regression coefficients (results of multiple linear regression analyses) or odds ratios (results of multiple logistic regression analyses) of presence of pet (versus no pet) and significance $(P<.05)$, corrected for sociodemographic and objective health characteristics

Outcomes related to the use of healthcare

\begin{tabular}{|c|c|c|c|c|c|c|}
\hline & \multicolumn{2}{|l|}{$\begin{array}{l}\text { Number of GP } \\
\text { consultations }\end{array}$} & \multicolumn{2}{|l|}{$\begin{array}{l}\text { Number of MS } \\
\text { visits }\end{array}$} & \multicolumn{2}{|c|}{$\begin{array}{l}\text { Use of mental } \\
\text { healthcare }\end{array}$} \\
\hline & $\beta$ & $P$ & $\beta$ & $P$ & OR & $P$ \\
\hline \multicolumn{7}{|l|}{ No pet (ref). } \\
\hline Cat & .02 & .61 & -.02 & .51 & 2.76 & .02 \\
\hline Dog & .03 & .28 & .03 & .41 & 1.81 & .23 \\
\hline Cat and dog & .04 & .21 & -.03 & .35 & 4.16 & .05 \\
\hline $\begin{array}{l}\text { Other pet (than } \\
\text { cat or dog) }\end{array}$ & .04 & .21 & -.04 & .23 & 1.36 & .69 \\
\hline \multicolumn{7}{|c|}{ Confounding variables ${ }^{\mathrm{a}}$} \\
\hline Age & & & -.10 & .002 & & \\
\hline Education level & & & & & 1.70 & .008 \\
\hline $\begin{array}{l}\text { Diagnosis: } \\
\text { cardiovascular }\end{array}$ & -.12 & .03 & & & & \\
\hline Diagnosis:arthritis & -.14 & .001 & & & & \\
\hline $\begin{array}{l}\text { Diagnosis: } \\
\text { musculoskeletal }\end{array}$ & -.09 & .02 & & & & \\
\hline $\begin{array}{l}\text { Number of chronic } \\
\text { diseases }\end{array}$ & .12 & .004 & & & & \\
\hline $\begin{array}{l}\text { Severity of phys. } \\
\text { disability }\end{array}$ & .16 & .007 & .20 & .001 & & \\
\hline $\begin{array}{l}\text { Locomotive and } \\
\text { sensory lim. }\end{array}$ & .22 & .04 & & & 4.43 & .03 \\
\hline \multicolumn{7}{|l|}{ Model statistics } \\
\hline$F / \chi^{2}(d f)$ & $F(21,1039)=3.44$ & $<.001$ & $F(21,1051)=3.78$ & $<.001$ & $\chi^{2}(21)=44.71$ & .002 \\
\hline $\begin{array}{l}\text { OLS } R^{2} / \\
\quad \text { Nagelkerke } R^{2}\end{array}$ & .07 & & .07 & & .12 & \\
\hline
\end{tabular}

Corrected for gender, age, educational level, marital status, number and type of chronic diseases, type and severity of physical disability

a only variables with significant effects shown 